\title{
Kajian Kesiapan Masyarakat Menerima Penggunaan Teknologi Augmented Reality Studi kasus: Desain Kemasan Oleh-oleh UMKM Khas Jawa Barat
}

\author{
Monica Hartanti dan Nina Nurviana \\ Desain komunikasi Visual, Fakultas Seni Rupa dan Desain, Universitas Kristen Maranatha \\ e-mail: monica26hartanti@gmail.com
}

\begin{abstract}
Abstrak-Digitalisasi adalah salah satu tanda bahwa saat ini Indonesia telah memasuki era Industri 4.0. Industri makanan dan minuman merupakan salah satu dari lima industri yang menjadi fokus implementasi Industri 4.0 di Indonesia, termasuk didalamnya adalah makanan oleh-oleh yang diproduksi oleh jutaan UMKM. Makanan oleh-oleh terkait dengan pariwisata dan desain kemasannya dapat menjadi duta budaya untuk menyampaikan identitas kelokalan sebuah daerah tertentu. Augmented Reality (AR) merupakan salah satu teknologi yang digunakan untuk mendukung industri 4.0, hal ini juga sesuai dengan Roadmap Making Indonesia 4.0 tahun 2018. Adapun objek studi yang dipakai dalam penelitian ini adalah karya Tugas Akhir Mahasiswa tentang kemasan dodol Stroberi khas Ciwidey-Jawa Barat. Penelitian ini membandingkan desain kemasan yang menggunakan teknologi cetak saja dengan desain kemasan yang dilengkapi teknologi $A R$. Penelitian menggunakan metode Triangulasi, yang menggabungkan Metode kualitatif dalam bentuk FGD dengan metode kuantitatif dalam bentuk kuesioner sebagai pelengkap. Luaran penelitian ini mengkaji kesiapan masyarakat dalam menerima teknologi AR melalui media desain kemasan.Temuan penelitian ini mengungkapkan bahwa responden menganggap AR adalah teknologi yang masih baru.Di kemudian hari, teknologi AR pada desain kemasan berpotensi sebagai alat promosi dan dapat memuat berbagai informasi, salah satunya adalah sebagai duta budaya.Sebagian besar responden menganggap teknologi $A R$ lebih sesuai untuk anak muda. Kelokalan akan lebih terasa, setelah ditambahkan teknologi $A R$ dalam elemen desain kemasan.
\end{abstract}

Kata Kunci: Augmented Reality, Desain Kemasan Makanan oleh-oleh, UMKM

Abstract-Digitalization is one sign that Indonesia has entered the Industrial 4.0 era. The food and beverage industry is one of the five industries that are the focus of the implementation of Industry 4.0 in Indonesia, including souvenirs produced millions by UMKM. Food souvenirs related to tourism and packaging design can be cultural ambassadors to convey the local identity of a particular region. Augmented Reality (AR) is one of the technologies used to support industry 4.0, and this is also by the Making Indonesia 4.0 Roadmap in 2018. The object of study used in this study is the Student Final Project work on the packaging of typical Strawberry-West Java dodol. This study compares packaging designs that use print technology only with packaging designs that are equipped with AR technology. The study uses the Triangulation method, which combines qualitative methods in the form of FGD with quantitative methods in the way of questionnaires as a compliment. The output of this study examines the readiness of the community in accepting AR technology through media packaging design. The findings of this study reveal that respondents consider $A R$ to be a new technology. At a later time, $A R$ technology in packaging design has the potential as a promotional tool and also contains various information, one of which is as a cultural ambassador. Most respondents consider AR technology more suitable for young people. Locality will be more pronounced, after adding AR technology in packaging design elements.

Keywords: Augmented Reality, Food's Gift Packaging Design, UMKM

\section{PENDAHULUAN}

Indonesia pada saat ini telah memasuki era Industri 4.0.Pada bulan April 2018 Pemerintah melalui Kementrian Perindustrian mencanangkan Roadmap Making Indonesia 4.0. Program ini meliputi 5 jenis industri yaitu: Industri makanan minuman, Otomotif, Elektronik, Kimia dan Tekstil. Industri makanan dan minuman sangat luas, yang menjadi pilihan adalah makanan oleh-oleh, makanan yang dijual di toko atau tempat wisata untuk para wisatawan baik dalam negeri maupun luar negeri untuk dibawa pulang sebagai oleh-oleh, dalam hal ini bukan makanan kuliner yang dinikmati di tempat makan. Makanan oleh - oleh mempunyai peran strategis, di Indonesia produk makanan oleh-oleh sebagian besar dibuat oleh UMKM (Usaha Mikro Kecil dan Menengah) dan di Indonesia pada tahun 2017 terdapat 57 juta UMKM adalah penggerak Ekonomi Nasional. [1]

Tabel 1: Tabel Pengeluaran perkapita Jawa Barat 2010-2017
\begin{tabular}{|l|l|l|l|l|l|l|l|l|l|}
\hline \multirow{2}{*}{ Kode } & Kab/Kota & \multicolumn{6}{|l}{ Pengeluaran per Kapita Disesuaikan (000 Rp PPP) } \\
\cline { 3 - 10 } & 2010 & 2011 & 2012 & 2013 & 2014 & 2015 & 2016 & 2017 \\
\hline 3200 & $\begin{array}{l}\text { Jawa } \\
\text { Barat }\end{array}$ & 9174 & 9249 & 9325 & 9421 & 9447 & 9778 & $\begin{array}{l}10 . \\
035\end{array}$ & $\begin{array}{l}10 \\
285\end{array}$ \\
\hline 3204 & Bandung & 8740 & 8797 & 8846 & 8978 & 8999 & 9375 & 9580 & 9854 \\
\hline
\end{tabular}

Sumber: https://jabar.bps.go.id/statictable/2018/05/15/575/ Pengeluaranper-kapita- 
Makanan oleh-oleh juga mempunyai peran strategis pada rangkaian kepariwisataan (Tabel 1). Oleh-oleh menjadi salah satu kebutuhan bagi orang yang bepergian ke suatu tempat apakah itu kota atau tempat wisata. Perkembangan informatika, moda transportasi, pembangunan infrastruktur dan naiknya pengeluaran per kapita mengindikasikan meningkatnya masyarakat bepergian di wilayah Indonesia maupun luar negeri. Sektor pariwisata menjadi primadona di Indonesia seperti diberitakan di bawah ini "Perolehan devisa negara dari sektor pariwisata sejak tahun 2016 sudah mengalahkan pemasukan dari migas dan di bawah pemasukan dari CPO. Diperkirakan pada tahun 2019, sektor pariwisata menjadi penyumbang utama devisa utama Indonesia," ujar Menteri Pariwisata Arief Yahya di Kantor Staf Presiden, Jakarta Pusat [2].

Makanan oleh-oleh tidak terlepas sendiri, makanan wajib menggunakan kemasan yang memiliki berbagai fungsi yaitu, sebagai pelindung, menunjukkan identitas, menyampaikan informasi, memuat konsep, memamerkan citra, menyentuh emosi, ergonomik dan sebagainya. Dalam kaitannya dengan pariwisata, kemasan dapat dijadikan sebagai duta budaya untuk menyampaikan ciri khas lokal suatu daerah. Dikarenakan fungsi tersebut, maka Kemasan makanan oleh-oleh seyogyanya memuat identitas kelokalan. Identitas yang disampaikan melalui desain kemasan tidak hanya berguna sebagai unsur estetik saja namun juga menjadi sebuah sarana pengenalan kearifan lokal yang terkandung di dalamnya [3].

Desain Kemasan termasuk subsektor Desain yang merupakan salah satu dari 15 Industri Kreatif Indonesia. Dalam lingkup pendidikan tinggi Desain Komunikasi Visual, Desain kemasan ditempatkan dalam mata kuliah elektif; menjadi salah satu tugas dari mata kuliah Mayor; dalam mata kuliah Branding; juga menjadi topik dari Tugas Akhir mahasiswa.

Mengingat program restrukturisasi pemerintah dalam merespon perubahan percepatan teknologi dalam Roadmap Making Indonesia 4.0, maka Kementrian Perindustrian mengimplementasikan sejumlah strategi yang melibatkan beberapa pemangku kepentingan, mulai dari institusi pemerintahan, asosiasi dan pelaku industri, hingga unsur akademisi. Institusi pendidikan harus merespon dengan melengkapi kurikulum perkuliahan agar dosen dan mahasiswa dapat menjadi elemen pendukung Making Indonesia 4.0.Dalam lingkup pendidikan tinggi desain, hal tersebut diwujudkan dengan pemanfaatan teknologi dalam beberapa tugas kuliah dan tugas akhir mahasiswa telah menggunakan QR Code dan AR (Augmented Reality) yang banyak diaplikasikan pada tugas desain yang berbentuk game, buku interaktif, signage, kampanye; dan masih sedikit yang diaplikasikan pada desain kemasan makanan.

Teknologi AR, yang memadukan dunia nyata dan maya bersama-sama, muncul sebagai salah satu teknologi paling menarik sebagai intelligent packaging untuk beberapa merek makanan dan minuman. Kemasan AR merupakan salah satu teknik pemasaran dengan elemen interaktif yang dimasukkan dalam kemasan agar kemasan terlihat lebih menonjol dari pesaing, sehingga diharapkan mampu mendorong penjualan. Desain kemasan ini menggabungkan cetak dengan digital yang dapat dipindai konsumen dengan smartphone untuk memainkan pesan audio yang dapat menciptakan pengalaman lebih mendalam bagi pemirsanya.

Teknologi ini juga memungkinkan merek untuk memberikan pengalaman imersif (sebuah pengalaman yang bisa membentuk rasa "ada di sana" serta menawarkan kesempatan untuk secara pribadi terlibat dalam sebuah cerita) kepada konsumen melalui investasi yang berpotensi rendah. Biaya yang dikeluarkan hanya pada pengembangan aplikasi awal dan desain grafis dan proses cetaknya juga tidak memerlukan material tambahan [4].

Pemanfaatan QR dan AR pada kemasan produk makanan sudah banyak digunakan oleh perusahaan di luar negeri (Gambar 1 dan 2). Sebagai contohnya, Produk Tomato Ketchup-Heinz, menggunakan teknologi augmented reality aplikasi Blippar membuat buku resep pop-out seketika saat kamera ditempatkan di atas produk, kemudian resepnya dapat diunduh sebagai PDF [5].

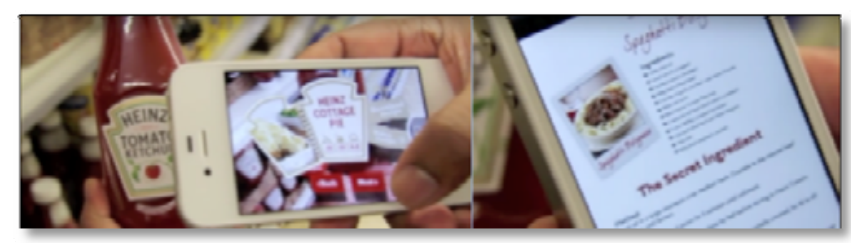

Gambar 1. Salah satu contoh pemanfaatan QR dan AR pada kemasan produk makanan merk Heinz berupabuku resep pop-out Heinz Sumber: screenshoot from

https://www.thedrum.com/news/2011/10/27/heinz-launchesketchup-augmented-reality-trial-blippar

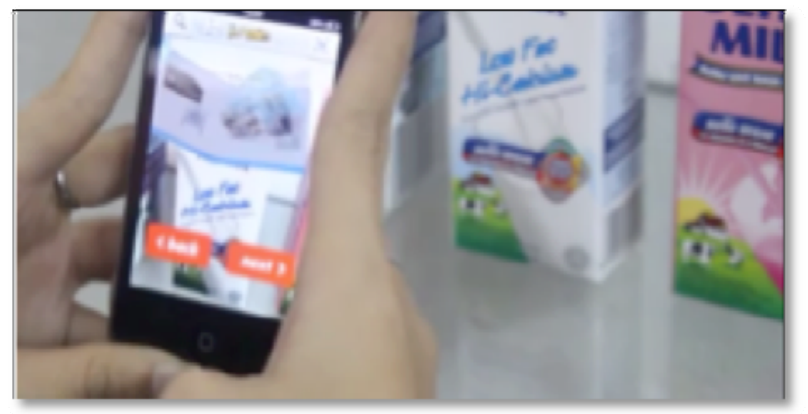

Gambar 2. Salah satu contoh pemanfaatan $Q R$ dan AR pada kemasan produk minuman merk Ultramilk AR

Sumber: https://www.youtube.com/watch?v=LsAmlNup7fE

Keunikan bisa membuat sebuah desain kemasan terlihat atraktif, karena hal itu akan mempengaruhi emosi konsumen terhadap pilihan produknya [6]. Teknologi AR pada kemasan produk makanan dan minuman di Indonesia sejauh ini masih terbatas pada perusahaan berskala besar seperti produk Ultra Milk. Dengan biaya produksi tidak mahal dan pengunduhan AR yang relatif mudah bagi konsumen saat ini, maka besar kemungkinan teknologi ini akan menjadi salah satu keunikan yang akan menambahkan nilai yang kompetitif pada pada desain kemasan di Indonesia.

Pemanfaatan AR yang belum populer di kalangan produsen dan pendesain kemasan makanan oleh-oleh khas Jawa Barat, menjadi menarik untuk dikaji lebih dalam. Objek studi dalam penelitian ini adalah dua desain kemasan dodol Stroberi khas Ciwidey. Sample pertama menggunakan teknologi cetak umum. Sample kedua menggunakan teknologi cetak umum yang dilengkapi QR code dan aplikasi Zappar sebagai AR-nya. Penelitian ini 
menggunakan metode Triangulasi dengan metode kualitatif lebih dominan dalam bentuk FGD diikuti dengan metode kuantitatif dalam bentuk kuesioner kepada 82 responden sebagai pelengkap untuk mengetahui kesiapan masyarakat dalam menerima teknologi AR melalui media desain kemasan makanan oleh-oleh, berkaitan dengan fungsi kemasan makanan oleh-oleh tersebut sebagai duta budaya lokal.

\section{Augmented Reality Sebagai Media Baru Pemasaran Produk Masa Kini}

Ketika dunia semakin terintegrasi dengan teknologi, perancang produk digital harus mempertimbangkan orangorang yang menggunakan perangkat teknologi dalam kehidupan sehari-hari mereka.Teknologi media cetak dan digital memiliki keunggulan masing-masing. Media yang dicetak sifatnya nyata, mudah disimpan untuk digunakan di masa depan, dapat diteruskan kepada orang lain. Digital sifatnya cepat, terlihat lebih "keren", dapat dipersonalisasi, mudah diakses, dan saat ini semakin banyak digunakan oleh konsumen setiap harinya. Ketika media cetak terintegrasi dengan digital akan menghasilkan sesuatu yang bagus, terjadi hubungan simbiosis nyata yang menguntungkan keduanya.

Augmented reality (AR) adalah informasi virtual yang dirasakan oleh pemirsa melalui perangkat digital, seperti smartphone.AR merupakan teknologi yang berkembang dengan peluang implementasi di banyak pasar yang berbeda.AR telah menjadi alat pemasaran yang sukses secara eceran, dengan memberikan pengalaman tambahan bagi pembaca melalui smartphone mereka sendiri [7].

Dibandingkan dengan QR Codes, AR lebih fleksibel. Aplikasi ini dapat beralih "antara elemen video, situs web, situs e-commerce, media sosial, dan sebagainya, melalui media smartphone atau tablet pembaca." Pada saat sebuah media yang tercetak memasukkan AR kedalam konten cetaknya, hal tersebut menghadirkan faktor "keren" yang nyata bagi konsumen, sehingga membuat produsen atau pengiklan menjadi tertarik untuk memasukkan pesan tertentu dalam konten AR-nya.

AR berbeda dengan VR, walaupun keduanya memiliki kualitas yang sama tetapi menghasilkan pengalaman pengguna yang berbeda. VR sepenuhnya menggantikan persepsi pengguna tentang dunia nyata dengan dunia virtual. Di AR, pengguna masih sadar akan lingkungannya karena pengguna masih bisa melihat dunia nyata. AR dapat dirancang untuk memperkaya pengalaman manusia. Sebagai contohnya, aplikasi Heinz Ketchup AR memungkinkan pengguna untuk "membalik" resep yang berbeda pada label yang diubah secara digital pada botol saus tomat mereka; tidak hanya ini memberikan pengguna kemampuan untuk berinteraksi dengan produk, itu juga memungkinkan untuk lebih banyak informasi yang akan ditampilkan pada ruang yang sempit.

Teknologi AR juga memiliki keunggulan secara ekonomis, Kampanye iklan AR bisa jauh lebih murah daripada iklan cetak tradisional. Mind Commerce (2013, Section 4.0) melaporkan bahwa pada tahun 2011, iklan satu halaman penuh di Sports Illustrated's Swimsuit mengeluarkan biaya lebih dari $\$ 400,00$, sementara kampanye AR sederhana bisa serendah $\$ 5.000$. AR dapat menjadi pilihan pemasaran yang lebih ekonomis, tergantung pada tingkat kerumitan untuk aplikasi AR dibandingkan dengan media cetak.(Kendra, 2017).Walaupun demikian, AR pada kemasan dapat lebih efektif atau berfungsi dengan baik untuk kampanye promosi jangka pendek. Data dari GlobalData mengungkapkan bahwa, konsumen akan kehilangan minat dalam kemasan AR relatif cepat, terutama jika konten AR ini tidak dibaharui secara berkala [8].

\section{METODE}

Penelitian ini menggunakan metode Triangulasi yang menggabungkan lebih dari satu metode riset.Metode ini bertujuan untuk melakukan cek silang sebagai sarana menghasilkan data empiris yang lebih terpercaya. Populasi yang digunakan dalam dua metode ini berbeda, namun dengan bobot pertanyaan yang sama [9]. Dalam penelitian ini Metode kualitatif lebih dominan dalam bentuk FGD diikuti dengan metode kuantitatif kepada 82 responden sebagai pelengkap.

Pelaksanaan FGD mengundang peserta dari berbagai profesi yang secara langsung dan tidak langsung berkaitan dengan desain kemasan oleh-oleh seperti, dari kalangan Dinas Perindustrian dan Perdagangan sebagai ujung tombak dan pembina produk dan kemasan UMKM, kalangan pengusaha UMKM, akademis dosen Desain Komunikasi Visual, percetakan, desainer kemasan, desainer kerajinan, konsumen makanan oleh-oleh, wistawan. Adapun Pelaksanaan kuesioner online disebarkan dengan batasan responden yang berdomisili di Jawa Barat dan juga yang pernah berdomisili di Jawa Barat dengan rentang umur 1935, 36-66 tahun.

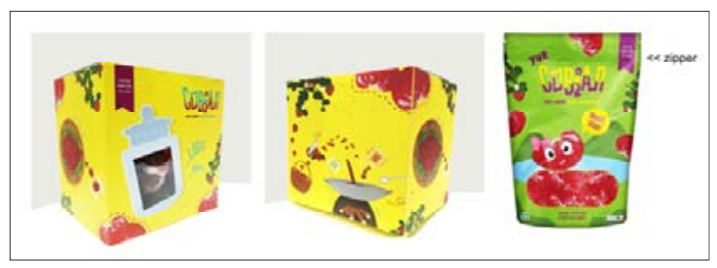

Gambar 3. Sample pertama penelitian--desain kemasan yang menggunakan teknologi cetak umum, dengan material karton, plastik transparan dan kemasan zipper stand up pouch.

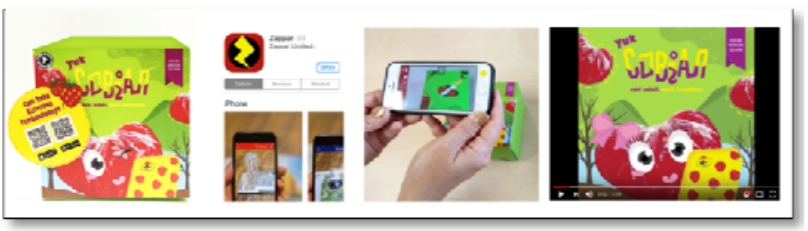

Gambar 4: Sample kedua penelitian--desain kemasan yang menggunakan teknologi cetak umum, dengan material karton, dilengkapi dengan teknologi cetak yang dilengkapi QR code yang dan aplikasi Zappar sebagai AR-nya (https://www.youtube.com/watch?v=CKFFJpLD-zk, 2018)

Pertanyaan yang diberikan kepada responden dalam FGD dan kuesioner dikaitkan dengan elemen yang ada pada metode ATUMICS.Metode ini adalah sebuah metode untuk mentransformasikan budaya tradisional ke bentuk produk baru yang modern. Kata transformasi berasal dari sebuah tindakan atau proses membentuk ulang, memodifikasi atau mengkonversi dalam sebuah manifestasi yang beragam. 
Langkah awal dalam transformasi tradisi adalah mengidentifikasi elemen tradisi potensial yang berharga dan dapat dikembangkan.Tahap selanjutnya mengindentifikasi elemen tradisi yang dapat diintegrasikan dengan teknologi kontemporer. Tahap ini akan memilah elemen tradisi dan modern yang harus ditambahkan, dibuang dan dipertahan sebelum masuk ke tahap terakhir yaitu mengintegrasikan elemen tersebut menjadi temuan baru.Dalam Teori ATUMICS Method, terdapat unsur Artefact, Technique, Utility, Material, Icon, Concept dan Shape yang merupakan akronim ATUMICS. Enam elemen dasar dari suatu artefak adalah: Technique - teknik produksi, teknologi, skill, alat. Utility - fungsionalitas, kegunaan - perminataan (demand), kebutuhan. Material - bahan alami, bahan sintetik, bahan smart. Icon - gambar, ornamentasi, warna, grafis. Concept - adat, kepercayaan, norma, nilai. Shape - bentuk, struktur, ukuran, gestalt [10].

Tabel 2. Hasil analisis Triangulasi pendapat responden berdasarkan FGD dan kuesioner menggunakan elemen metode ATUMICS.

\begin{tabular}{|c|c|}
\hline \multicolumn{2}{|r|}{ ATUMICS } \\
\hline $\begin{array}{l}\text { Hasil Analisa } \\
\text { Triangulasi } \\
\text { TECHNIC }\end{array}$ & $\begin{array}{l}\text { - Teknologi cetak pada desain kemasan sudah } \\
\text { familiar di Indonesia. } \\
\text { AR dianggap masih tidak efisien dari segi harga, } \\
\text { karena harus mengeluarkan biaya tambahan untuk } \\
\text { membeli aplikasi. } \\
\text { Desainer yang dapat membuat desain dengan } \\
\text { penambahan teknologi AR masih terbatas. } \\
\text { Di Indonesia, teknologi AR pada desain kemasan } \\
\text { hanya sesuai untuk diterapkan di kota besar, } \\
\text { karena akan memberi nilai jual lebih tentu saja } \\
\text { dengan konten yang harus sesuai dengan pangsa } \\
\text { pasar. }\end{array}$ \\
\hline \multicolumn{2}{|r|}{ ATUMICS } \\
\hline $\begin{array}{l}\text { Hasil Analisa } \\
\text { Triangulasi } \\
\text { UTILITY }\end{array}$ & $\begin{array}{l}\text { Desain kemasan yang dicetak memenuhi fungsi } \\
\text { sebagai wadah, higienis, modern, informatif, dan } \\
\text { dapat melindungi produk. } \\
\text { Desain yang terlalu modern dari sisi grafis dan } \\
\text { bentuk dan kurang menunjukkan ciri khas } \\
\text { daerahnya. Dikhawatirkan tidak layak sebagai } \\
\text { desain kemasan souvenir oleh-oleh. } \\
\text { Teknologi motion dan AR pada desain } \\
\text { kemasandapat menyampaikan budaya lokal, } \\
\text { dianggap lebih suistanable karena dapat diakses } \\
\text { berulang kali. } \\
\text { Dikarenakan teknologi ini belum familiar di } \\
\text { masyarakat Indonesia, maka teknologi AR pada } \\
\text { desain kemasan dianggap berfungsi tersier. }\end{array}$ \\
\hline
\end{tabular}

\section{Objek Studi Penelitian}

Penelitian ini adalah bagian dari studi untuk menghasilkan sebuah prototipe modul desain kemasan kreatif makanan oleh-oleh Jawa Barat yang merupakan hasil transformasi budaya tradisional di era digital. Berdasarkan survei awal yang telah dilakukan, tim peneliti membuat simulasi objek penelitian berupa desain kemasan makanan oleh-oleh dodol Stroberi khas Ciwidey Jawa Barat yang telah dirancang dalam Tugas Akhir mahasiswa kami bernama Birgita Nindya Karina. Desain tersebut kemudian dikembangkan lebih oleh peneliti dengan menambahkan teknologi AR, menggunakan aplikasi Zappar.

Terdapat dua sample desain kemasan.Sample pertama menggunakan teknologi cetak umum, dengan material karton, plastik transparan dan kemasan zipper stand up pouch (Ganbar 3) Sample kedua menggunakan material yang sama dengan sample pertama namun dengan teknologi cetak yang dilengkapi QR code yang dan aplikasi Zappar sebagai AR-nya (Gambar 4). Teknologi ini memungkinkan pengguna melalui ponselnya dapat mengunduh aplikasi sehingga dapat melihat informasi secara visual dan audio.

Konsep desain kemasan makanan oleh-oleh dodol Stroberi khas Ciwidey Jawa Barat ini ingin menampilkan produk secara lebih trendi, alami dan berciri kelokalan Sunda.Grafis yang ditampilkan mengusung ciri geografis Ciwidey, proses pembuatan dodol stroberi secara alami, menggunakan tipografi bergaya aksara Sunda dan teks berbahasa Sunda. Setelah aplikasi AR dijalankan, konten desain akan bergerak dan akan terdengar musik khas Sunda.

\section{HASIL DAN PEMBAHASAN}

Berikut adalah hasil rangkuman pendapat responden dalam FGD dan kuesioner menggunakan elemen metode ATUMICS yang kemudian dianalisis dengan metode Triangulasi (Tabel 2 dan 3).

Tabel 3. Hasil analisis Triangulasi pendapat responden berdasarkan FGD dan kuesioner menggunakan elemen metode ATUMICS (Lanjutan)

\begin{tabular}{|c|c|}
\hline \multicolumn{2}{|r|}{ ATUMICS } \\
\hline $\begin{array}{l}\text { Hasil Analisa } \\
\text { Triangulasi } \\
\text { MATERIAL }\end{array}$ & $\begin{array}{l}\text { Material pada desain kemasan yang dicetak } \\
\text { mudah ditemukan di pasaran, terlihat umum dan } \\
\text { kurang inovatif, sehingga pada desain grafis dan } \\
\text { cutting-nya perlu lebih inovatif. } \\
\text { Perbandingan gramatur kertas yang dipilih harus } \\
\text { disesuaikan dengan ukuran kemasan. } \\
\text { Smart material dengan penambahan QR codes } \\
\text { dan AR berkesan lebih modern, canggih, } \\
\text { inovatif sehingga memberi daya tarik dan } \\
\text { pengalaman baru bagi konsumen. }\end{array}$ \\
\hline $\begin{array}{l}\text { Hasil Analisa } \\
\text { Triangulasi } \\
\text { ICON }\end{array}$ & $\begin{array}{l}\text { Penggunaan ikon pada desain desain kemasan } \\
\text { tidak perlu terlalu ramai, agar pesan } \\
\text { tersampaikan maksimal. } \\
\text { Untuk menyampaikan kesan alami dan } \\
\text { kelokalan, konten AR sebaiknya menggunakan } \\
\text { ikon desain yang tidak kekanak kanakan. } \\
\text { Informasi dan grafis pada desain kemasan cetak } \\
\text { dapat dikembangkan tanpa batas. } \\
\text { Perlu ada kesatuan estetik dan fungsional } \\
\text { tentang kemudahan unduh QR codes dan AR, } \\
\text { sehingga konten lokal bisa dilihat konsumen. }\end{array}$ \\
\hline $\begin{array}{l}\text { Hasil Analisa } \\
\text { Triangulasi } \\
\text { CONCEPT }\end{array}$ & 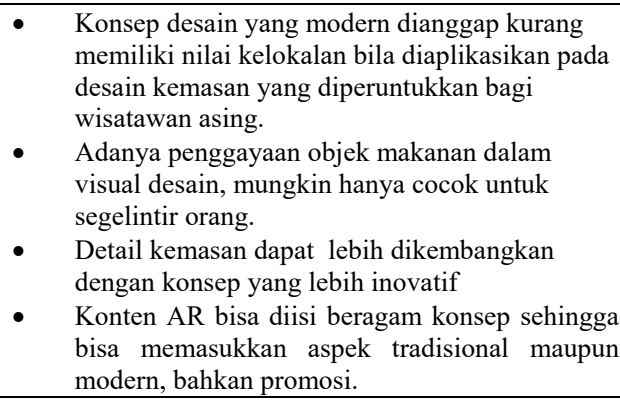 \\
\hline $\begin{array}{l}\text { Hasil Analisa } \\
\text { Triangulasi } \\
\text { SHAPE }\end{array}$ & 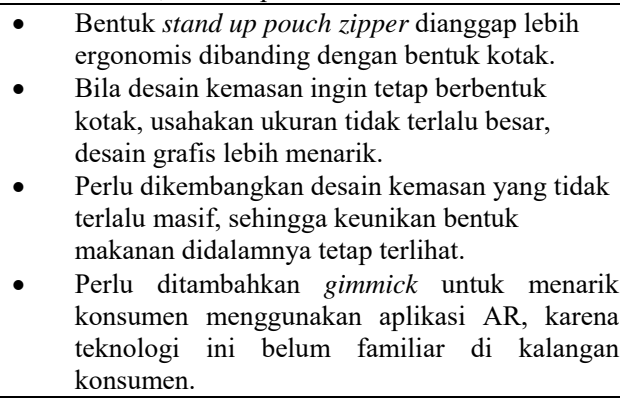 \\
\hline
\end{tabular}




\section{KESIMPULAN/RINGKASAN}

Temuan penelitian ini mengungkapkan bahwa AR merupakan teknologi baru bagi konsumen, produsen dan juga bagi dinas perdagangan dan perindustrian.Konsumen dan produsen masih merasa nyaman dengan teknologi dan desain kemasan yang ada saat ini, dengan bentuk kemasan yang lebih unik, dan ukuran yang tidak terlalu besar. Teknologi AR saat ini baru sesuai untuk diterapkan di kota besar saja dengan pangsa pasar anak muda. Kelokalan akan lebih terasa bila konten AR dari segi visual dan suara dibuat lebih realistik. Dapat disimpulkan bahwa saat ini masyarakat masih belum siap menggunakan teknologi AR dalam media desain kemasan makanan oleh-oleh. Walaupun demikian, teknologi AR berpotensi untuk dikembangkan sebagai alat promosi efektif dari sisi biaya, tenaga dan waktu. Melalui Teknologi ini dapat disampaikan informasi yang lebih luas berkaitan dengan produk, budaya lokal, tempat wisata dalam visualisasi gambar yang digerakkan dan didukung oleh suara, sehingga dapat menambah nilai fungsional pada desain kemasan makanan oleh-oleh sebagai duta budaya.

\section{DAFTAR PUSTAKA}

[1] Bisnis Tempo. Bisnis UMKM Diklaim sebagai Penggerak Ekonomi Terbesar Indonesia. (2017), diunduh https://bisnis.tempo.co/read/835486/umkm-diklaimsebagai-penggerak-ekonomi-terbesar indonesia/full\&Paging=Otomatis/10/08/2018.

[2] Chandra, Ardan A., Damarjati D. (2017). Tiga Tahun Jokowi-JK, Pariwisata Sumbang Devisa Terbesar Kedua.Diunduh dari https:/finance.detik.com/beritaekonomi-bisnis/d-3687715/tiga-tahun-jokowi-jk-pariwisatasumbang-devisa-terbesar-kedua/10/08/2018.
[3] Sarjani N.K.P, Cahyadi. 2016. Identitas Budaya Lokal Pada Desain Kemasan Baline Chocolate, 4 (1), Institut Seni Indonesia Denpasar. Segara Widya.

[4] Gould, Summer (2014). Can Augmented Reality Add Value to Print?. Diunduh dari https://www.targetmarketingmag.com/article/canaugmented-realityadd-value-print/all/13/08/2018.

[5] Macleod, Ishbel. (2011). Heinz launches augmentedreality trial for ketchup with Blippar. Diunduh dari https://www.thedrum.com/news/2011/10/27/heinzlaunches-ketchup-augmented-reality-trial-blippar.

[6] Hartanti, M., Nurviana, N., (2016). Kajian Visual Kemasan Masakan Tradisional Instan, studi kasus kemasan nasi-nasian instan. (belum dipublikasikan). Diunduh dari http://art.maranatha.edu/resume/monicahartanti/?lang=en/11/08/2018.

[7] Wiley, Kendra, (2017), From Your Phone To Your Home: An Augmented Reality Brand Experience For High-End Furniture, Thesis, Texas State University, San Marcos, Texas. Diunduh dari https://digital.library.txstate.edu/bitstream/handle/1087 7/6730/Wiley_Kendra_Thesis.pdf?sequence $=1 \&$ isAllo wed=y. 25/07/2018/12.00.

[8] Corbin, Tony. (2018). Novelty of Augmented Reality Packs Could Wear Off, Warns Off, Warns Global Data. Diunduh dari

https://www.packagingnews.co.uk/news/markets/active -intelligent-packaging/globaldata-augmented-realityshort-term-solution-29-03-2018/13/08/2018.

[9] Sarwono, Jonathan. (2011). Mixed Methods: Cara Menggabung Riset Kuantitatif dan Riset Kualitatif Secara Benar, Jakarta: Elex Media Komputido.

[10] Nugraha, A., (2012). Transforming Tradition: A Method for Maintaining Tradition in a Craft and Design Context. Helsinki: Unigrafia. 